\title{
The Effectiveness of Robotics Competitions on Students' Learning of Computer Science
}

\author{
Fatima KALOTI-HALLAK, Michal ARMONI, \\ Mordechai (Moti) BEN-ARI \\ Weizmann Institute of Science, Israel \\ e-mail:fatima.kaloti.hallak@gmail.com,michal.armoni@weizmann.ac.il, \\ moti.ben-ari@weizmann.ac.il
}

\begin{abstract}
This work investigates students' learning of computer science (CS) as part of a research project on students' learning of and attitudes toward STEM (Science, Technology, Engineering, and Mathematics) subjects during their participation in robotics activities. The population consisted of groups of middle-school students (ages 13-15 years) who participated in the FIRST ${ }^{\circledR}$ LEGO $^{\circledR}$ League competition. The methodology used is both qualitative and quantitative using questionnaires, observations and interviews during the school year 2012-2013, and mainly group interviews during the school year 2013-2014. A representational model was used during the interviews to facilitate externalizing the students' understanding of STEM concepts. The analysis used the revised Bloom Taxonomy (BT) to study the students' meaningful learning. Two CS concepts were investigated: input-output and interfacing with sensors. The results showed that during their preparation for the competition, almost all the students demonstrated meaningful learning, although some students reached higher levels of the BT than others.
\end{abstract}

Keywords: computer science, middle-school, extra curriculum, robotics, competitions, FLL.

\section{Introduction}

Recently, the number of schools that participate in robotics activities has increased and a few of them have tried to integrate such activities into their school curriculum. In order to improve learning of STEM subjects and to increase enrollment, educators have suggested that robotics be integrated into schools at many levels from middle school through college (Anderson et al., 2011). In particular, competitions like the FIRST $^{\circledR}$ LEGO $^{\circledR}$ League (FLL) competition are the primarily type of robotics activities in schools. Most of the existing literature shows that students can be motivated and enthusiastic about participation in robotics activities. However, there are very few empirical studies that demonstrate improvement in students' learning of STEM. This research project focuses on investigating students' learning of and attitudes toward each of the STEM subjects during their participation in robotics activities (Kaloti-Hallak, 2014). This paper presents results on the learning of CS; subsequent publications will present 
the results on learning of other STEM subjects, and the results of the investigation of students' attitudes.

Our research concerned the achievement of learning by middle-school students participating in the FLL competition. The data was collected by using a variety of instruments: pre- and post-questionnaires, observations and interviews. The analysis was primarily qualitative based on the cognitive process dimension of the (Revised) Bloom Taxonomy (BT) (L. Anderson et al., 2001). Quantitative analyzing of the questionnaires was also conducted.

The research question (limited to the scope of this article) is:

What scientific content knowledge do students learn during their participation in the FLL competition?

a. To what extent is CS content knowledge is learned?

b. To what extent is the students' learning meaningful?

The background is given in Section 2, followed by the presentation of the methodology in Section 3. The data analysis is in Section 4, the findings are presented Section 5, and they are discussed in Section 6 and concluded in Section 7.

\section{Background}

\subsection{Robotics in education}

Robots have been used in both community outreach programs and academic institutions at all educational levels (M. Anderson et al., 2011), even in special needs education (Virnes et al., 2008). Robots, as physically manifested computing devices, inherently show students how the programs that they write can impact the real world. Robots are generally used to motivate students' interest in further study of science and technology (Lauwers et al., 2009). It facilitates hands-on programming, increasing the quality of interaction between the child and the robot (a command to the robot is followed by the feedback of the robot's behavior), and improves the quality of instruction and intervention (Virnes et al., 2008).

Fagin and Merkle (2003) examined the effectiveness of robotics in encouraging firstyear university students to select computer science or computer engineering. In general, results were negative: test scores were lower in the robotics sections than in the nonrobotics ones, and the use of robots did not have any measurable effect on students' choice of discipline. Summet et al. (2009) assigned a robot to each student, defined a curriculum and developed an interactive environment. They claimed that the approach was successful, and that it encouraged more students' to enroll in a higher level CS classes. However, the authors were somewhat equivocal about the results, noting that the "robots approach does not appear to be doing harm."

Lauwers, Nourbakhsh and Hamner (2009) worked with CS educators to investigate the features of robots that are well-suited to the learning goals of CS in an introductory university-level CS course. The results were compared with courses taught previously 
without robots. They found a significant increase in students' positive attitudes and motivation to learning with robotics activities; the students also completed all the assignments and tests scores were significantly higher than in prior years. However, retention did not improve.

Martin (2006) claimed that the physical imperfections in robots and the environment can help students deal with unexpected problems better than computer-only activities. Studies have shown that students' response to a problem can be inadequate, because they engage in trial-and-error until they succeed or give up. For example, Sullivan (2008) showed that even academically advanced middle-school students who were motivated to join a robotics research group and eventually succeeded in solving problems did so through trial-and-error.

\subsection{Robots and Robotics Competitions}

Several kinds of robots have been used in education. For example, the Scribbler robot (Summet et al., 2009), the iRobot Create (Anderson et al., 2011), the Topobo robot (Virnes et al., 2008), or the Thymio (Riedo et al., 2013). One of the most widely used educational robots is the LEGO $^{\circledR}$ MINDSTORMS ${ }^{\circledR}$ kit. Robots consist of the mechanical robot platform, motor(s), an onboard computer and a system for communicating with a desktop computer used for programming, sensors and software for programming the robot. The software can be a visual programming environment, or it can be an adaptation of an ordinary programming language.

Most schools engage in the robotics activities through competitions, including: the Trinity College Fire-Fighting Home Robot Contests (TCFFHRC) (http://www . trincoll.edu/events/robot/) (Verner and Hershko, 2003), the Botball contest (http: / / www . botball . org/) (Miller and Stein, 2000), Robo Fest (http : / / robofest.net), and the FLL (http://firstlegoleague.org) or the FIRST Robotics Competition (http: / / www. usfirst.org/roboticsprograms/frc) (Melchior et al., 2005).

The FLL is a yearly competition for children in grades 4 to 8 using the LEGO $^{\circledR}$ MINDSTORMS ${ }^{\circledR}$ kit. The kit contains LEGO ${ }^{\circledR}$ bricks as well as motors, gears and sensors. Programs are written on a personal computer using a visual programming environment called LabView and downloaded to the NXT controller, so that the robot can run the program without being tethered to the computer. Students can download instructions for constructing several robots; normally, one or more of these robots are built to obtain experience before trying to design a new robot.

The FLL competition consists of three parts:

1) The students are required to design and build a robot that fulfils missions in a scenario that changes every year; robots that fulfil the largest number of missions in the shortest time win the competition.

2) A scientific project that challenges students to create an innovative solution for a specific problem.

3) Developing core values that emphasize teamwork. 
My research focuses on the first part of the competition that requires students to design and build robots.

The FLL competition's missions are designed according to an authentic theme; in year 2012-2013, the first year of the research was conducted, the FLL theme was "Senior Solution" and contained missions that simulate assisting senior citizens in areas that they may find difficult. A score is associated with each mission and can be accumulated. In year 2013-2014, the FLL theme "Nature's Fury" and contained missions that simulate helping people prepare, stay safe or rebuild in case of natural disaster. Yearly competitions have different themes, but they have common goals: promoting robotics in education and encouraging systems-thinking, problem solving, and teamwork skills.

We choose to work within the context of the FLL competition for several reasons: (i) it offers a different theme each year that is related to STEM and real world problems; (ii) requires that the students make a presentation on the subject; (iii) it targets students as young as 9 years old; (iv) it is the one that is available to us.

\subsection{The Bloom Taxonomy and Meaningful Learning}

The Bloom Taxonomy was first described in 1956 as a hierarchical model for the cognitive domain that organizes the cognitive aspects of learning into six hierarchical levels: knowledge, comprehension, application, analysis, synthesis, and evaluation (Bloom et al., 1956). Given its popularity through the years, the taxonomy has been condensed, expanded and reinterpreted in a variety of ways (Forehand, 2012; Johnson and Fuller, 2006). The model was revised by Anderson et al. (2001) with a number of significant changes to the terminology, structure and emphasis. The revised structure has two dimensions: a cognitive process dimension with the original categories of Remembering, Understanding, Applying, Analyzing, Evaluating, and Creating, and a knowledge dimension with the categories Factual, Conceptual, Procedural and Meta-Cognitive. The new version is referred to as the revised Bloom Taxonomy (Thompson et al. 2008). We chose to work with the revised BT because it appears to offer appropriate categories for evaluating students' meaningful learning.

Ausubel $(1963,2000)$ defined meaningful learning as the subsumption or incorporation of new learned material into the student's cognitive structures. The goal of meaningful learning is to teach students concepts that will be recalled and used; therefore, meaningful learning strategies must build complex knowledge structures in the learner's mind (Ausubel, 2000). It is commonly accepted today that generalizations cannot be presented or given to the learner, but can only be acquired as a product of problem-solving activities. Meaningful learning occurs when students build the knowledge and cognitive processes needed for successful problem solving. The five categories of the taxonomy (understanding, applying, analyzing, evaluating and creating) are increasingly related to transfer, while the remembering category is related to retention (Mayer, 2002). 
Technology can make learning more meaningful. Howland, Jonassen and Marra (2011) present five characteristics that are necessary to achieve meaningful learning using technology: active, constructive, intentional, authentic, and cooperative. In constructionist learning (Turkle and Papert, 1991), students engage in active cognitive processing. The revised BT cognitive processes describe the range of students' cognitive activities in meaningful learning that it is the way students can actively engage in the process of constructing meaning (Mayer, 2002).

LEGO $^{\circledR}$ MINDSTORMS ${ }^{\circledR}$ are conjectured to facilitate meaningful learning (Miller, Nourbakhsh and Siegwart, 2008). Robotics competitions with LEGO ${ }^{\circledR}$ MINDSTORMS ${ }^{\circledR}$ require that students collaborate in order to accomplish the tasks required, such as the missions of an FLL competition. The students start with an assigned authentic project, and as they become more familiar with the technology, they achieve more control over constructing and programming the robot and can implement their own creative ideas.

\subsection{Computer Science Concepts}

Performing robotics activities requires mastery of CS concepts. Computer science encompasses far more than programming (Denning and McGettrik, 2005). Denning et al. (1989) coined the phrase discipline of computing to combine the analysis and abstraction of computer science with the abstraction and design of engineering. The discipline of computing is the systematic study of algorithmic processes that describe and transform information: their theory, analysis, design, efficiency, implementation and application. It includes nine subareas: algorithms and data structures, programming languages, architecture, numerical and symbolic computation, operating systems, software methodology and engineering, database and information retrieval systems, artificial intelligence and robotics, and human-computer communication. See Denning et al., (1989) for details of each subarea.

Among all the CS concepts that the students demonstrated, we chose to focus on two:

(a) input-output (not just from the screen and keyboard) which appears in the programming languages subarea;

(b) interfacing with sensors from artificial intelligence and robotics subarea.

These concepts were chosen because: (a) students displayed a range of engagement with the concepts during the robotics activities; (b) the concepts were not previously known by most of the students; and (c) the concepts touch on more than just programming, since students must identify the different sensors and their capabilities, understand how they can be used for input and output, as well as the algorithmic transformation of the input data to the output data.

The definitions of the concepts that we use here are based on robotics books such as Trobaugh (2010), Kumar (2009) and Martin (2001). In more detail: 
a. Input-output: Computer programs receive input data, perform computations and then produce output data. In robotics, the input comes from sensors that measure the dynamic environment of the robot (light, color, proximity, touch) and output (motors). This concept will be introduced when the students connect an input such as light sensor and output such as the motors to the NXT controller. The controller has four input connectors for sensors and three output connectors for motors. The expected learning outcomes can range from just identifying the input-output ports (limited learning) to explaining the difference between the input and output devices and how they work (more extensive learning), up to the highest level of devising new solutions based on these concepts.

b. Interfacing with sensors: Sensors in robotics can be used for detecting an object or for following a line on the mission table using a light or color sensor. The ultrasonic proximity sensor can detect this distance to an object and the touch sensor detects when the sensor touches something in the environment. The interface with these sensors is by programming the controller. The expected learning outcomes can range from identifying the techniques and algorithms used in interfacing with sensors (limited learning) to modifying the techniques or creating new ones (more extensive learning).

\section{Methodology}

\subsection{Population}

The research population consisted of middle-school students in Israel and the Palestinian Territories, aged 13-15 years, who participated in FLL robotics competition. The robotics activities were extracurricular, after school, on weekends and during vacations. Most of the teachers have no background in robotics; they are trained for a few months before they teach robotics and supervise the activities.

During the year 2012-2013, eight groups participated in the FLL competition. Six groups (Group 1, Group 2, Group 5, Group 6, Group 7 and Group 8), a total of 47 students (34 females and 13 males) participated in the competition for the first time, while Group 3 and Group 4, a total of 15 students (all female), had previous experience with the robotics. Ten of them had participated in the previous competition in 2011-2012.

The students who were interviewed by the researcher are referenced by $\mathrm{S}$ associated with a number. A summary of groups is presented in Table 1.

Five groups (Group 1, Group 2, Group 5, Group 6 and Group 7), a total of around 37 students (29 females and 8 males), who had participated in the 2012-2013 competition continued on to participate in the 2013-2014 competition. Some of the teachers were the same in both years, as were many of the students. Each group included students who participated in the previous year's competition, as well as new students who had never participated before in robotics activities. The school of Group 7 initiated a regular robotics class in 2013-2014 and added it to their curriculum. Six of the students who had 
never participated before in robotics activities participated in both the robotics class and the robotics competition. The interviews were conducted with two students (S16 and S17) who did not have experience in competitions, but who participated in the regular school robotics class. For two of the groups (Group 4 and Group 8) we were not able to collect data of their activities, and Group 3 did not participate in the competition for the year 2013-2014. A summary of the groups is presented in Table 2.

The robotics activities started around the first months of the school year and ended on the competition day, usually during the last two months of the school year.

The resources available to the students were the $L E G O^{\circledR}$ kit, together with its manual, online tutorials and books, and handouts provided by the organizers. In the absence of a fixed curriculum and textbook, the students searched for information from all these resources.

Table 1

Research participants in the school year 2012-2013

\begin{tabular}{llll}
\hline $\begin{array}{l}\text { Group } \\
\text { Number }\end{array}$ & $\begin{array}{l}\text { Students } \\
\text { and Gender }\end{array}$ & $\begin{array}{l}\text { Students with } \\
\text { experience in robotics }\end{array}$ & $\begin{array}{l}\text { Students } \\
\text { Interviewed }\end{array}$ \\
\hline 1 & $9 \mathrm{~F}$ & - & $\mathrm{S} 1, \mathrm{~S} 2, \mathrm{~S} 3$ \\
2 & $6 \mathrm{~F}$ & - & $\mathrm{S} 8, \mathrm{~S} 9$ \\
3 & $8 \mathrm{~F}$ & 4 & $\mathrm{~S} 12, \mathrm{~S} 13$ \\
4 & $7 \mathrm{~F}$ & 6 & - \\
5 & $7 \mathrm{M}$ & - & $\mathrm{S} 4, \mathrm{~S} 5$ \\
6 & $10 \mathrm{~F}$ & - & $\mathrm{S} 6, \mathrm{~S} 7$ \\
7 & $7 \mathrm{~F}$ & - & $\mathrm{S} 10, \mathrm{~S} 11$ \\
8 & $6 \mathrm{M}, 2 \mathrm{~F}$ & - & $\mathrm{S} 14, \mathrm{~S} 15$ \\
\hline Total & $\mathbf{6 2} \mathbf{( 4 9} \mathbf{~ F , ~ 1 3 ~ M ) ~}$ & $\mathbf{1 0 ~ F}$ & $\mathbf{1 5} \mathbf{( 1 1} \mathbf{~ F , ~ 4 ~ M ) ~}$ \\
\hline
\end{tabular}

Table 2

Research participants in the school year 2013-2014

\begin{tabular}{|c|c|c|c|c|}
\hline $\begin{array}{l}\text { Group } \\
\text { number }\end{array}$ & $\begin{array}{l}\text { Students } \\
\text { and gender }\end{array}$ & $\begin{array}{l}\text { Students with } \\
\text { experience in robotics }\end{array}$ & $\begin{array}{l}\text { Students } \\
\text { interviewed }\end{array}$ & Teachers \\
\hline 1 & $7 \mathrm{~F}$ & 3 & - & Different \\
\hline 2 & $5 \mathrm{~F}, 2 \mathrm{M}$ & 2 & - & Same \\
\hline 3 & \multicolumn{4}{|c|}{ Didn't participate in competition year 2013-2014 } \\
\hline 4 & \multicolumn{4}{|c|}{ Not able to collect data from this group } \\
\hline 5 & $6 \mathrm{M}$ & & - & Same \\
\hline 6 & $7 \mathrm{~F}$ & - & - & Same \\
\hline 7 & $\begin{array}{l}10 \mathrm{~F} \\
(6 \text { of whom } \\
\text { participated in } \\
\text { robotics class) }\end{array}$ & 4 & S16, S17 & Different \\
\hline 8 & \multicolumn{4}{|c|}{ Not able to collect data from this group } \\
\hline Total & 37 (29 F, 8 M) & $9 \mathbf{F}$ & $2 \mathbf{F}$ & \\
\hline
\end{tabular}




\subsection{Research Instruments}

The data collection instruments included (a) pre- and post-questionnaires consisting of Likert-scale items to investigate the students' attitudes toward learning STEM and robotics activities; (b) observations during the school year; (c) semi-structured interviews conducted by the researcher with 2-3 students from each group; and (d) group interviews conducted by the judges during the competition day ${ }^{1}$. The observations and the interview were recorded on video.

The interview used a Representational Model (RM), defined as an inscription, image, analogy, physical construction or computer simulation that facilitates the externalization of students' knowledge and understanding. Students were asked to express the design of their robots (including aspect of mechanics, electronics and software) graphically or in writing, and to instruct the robot to accomplish one of the FLL missions using flowcharts, pseudo-code, or any other notation of their choice. Before the interview, a table with materials that students might use to express their thoughts was prepared: paper, pencils, crayons, rulers, a protractor, and $\mathrm{LEGO}^{\circledR}$ pieces.

The students were asked to relate to three types of activities (tasks) in their representational models: a) the engineering of the robot; b) the mathematics required to instruct the robot to perform the missions; and c) the programming and CS concepts required. In this paper we focus on the programming and CS concepts. In each case, an alternative task was prepared to be used if the student did not cooperate in the initial task.

For example, the students had drawn a path that the robot should take to reach the mission's location, determined the distance and angles the robot should take, and decided on the functions the robot needs to perform, such as lowering a handle or picking something up. The students were now asked to write or draw the programming instructions and to explain these instructions. If the student couldn't write or draw the program instructions, a written program prepared in the NXT environment is presented as an alternative task and the students were asked to explain it.

\subsection{The Operationalization of Meaningful Learning of the CS Concepts ${ }^{2}$}

The categories or levels ${ }^{3}$ of the cognitive process dimension of the revised BT were used to analyze the meaningful learning of CS concepts during the robotics activities. The first level of the BT, remembering, promotes retention, while the five levels above remembering, promote transfer (Mayer, 2002). Mayer claims that in some subjects, you need to start with remembering in order to get to a meaningful learning goal, and we believe that this is true in robotics. However, in robotics, meaningful learning requires more of the students than simply recalling or recognizing factual knowledge.

\footnotetext{
${ }^{1}$ The first author was asked by the judges to participate in some of these interviews.

${ }^{2}$ Words in bold in this section and below refer to the categories of the revised BT and italic is used for the operational definition of each category.

${ }^{3}$ We use levels in preference to categories.
} 
Therefore, we required that students achieve higher levels than remembering in order to demonstrate meaningful learning. The higher the level the more meaningful learning the students gain.

For the concept of input-output, we merged the understanding and the applying levels, because if the students realize the concept they also need to implement the related techniques. We merged the analyzing and the evaluating levels, because if the students integrate knowledge related to the whole design, they are also differentiating, comparing and criticizing the different performances of their design.

As for the concept of interfacing with sensors, we merged the applying with the analyzing level, because when the students implement a solution to a task, they go directly to integrating knowledge related to the whole design and testing the solution.

The BT levels for the CS concepts were operationalized as follows:

1. Remembering: The students demonstrate the remembering level if they are:

a. (Input-output) naming, listing or memorizing facts and terms as they had been taught or mentioned before without demonstrating any meaningful grasp of the input-output functionality. For example, the students are mentioning the port sides of the NXT to attach the sensors and the sides for motors as they have been told without realizing the difference between them.

b. (Interfacing with sensors) naming, listing, memorizing or identifying the available sensors and the command(s) responsible for interfacing with those sensors. For example, the students are listing the available sensors as have been told without knowing or trying to use them.

2. Understanding: The students demonstrate the understanding level if they are:

a. (Input-output) realizing, recognizing and implementing the main ideas or knowledge of the input-output concept in a new problem. ${ }^{4}$ For example, the students are recognizing that the sensors are input devices and connect them through the input ports, same with motors connecting them through the output ports of the NXT.

b. (Interfacing with sensors) recognizing the facts (properties), techniques or algorithm related to the use of sensors' command(s). For example, the students are recognizing the NXT blocks responsible for operating the sensors. However, they are not trying to use any sensor.

3. Applying the students demonstrate the applying level if they are:

a. (For input-output this level was merged with understanding).

b. (Interfacing with sensors) using the relevant knowledge, techniques or algorithm to interface with the sensors in solving a problem. ${ }^{5}$ For example, the students $u$ se the light sensor to follow a black line on the mission table ground. They are using a specific technique.

4. Analyzing the students demonstrate the analyzing level if they are:

\footnotetext{
${ }_{5}^{4}$ For this concept, the definition refers to the merged understanding / applying level.

5 For this concept, the definition refers to the merged applying / analyzing level.
} 
a. (Input-output) explaining the related knowledge of the input-output and differentiating between their functionality in relation to the overall structure of the robot. ${ }^{6}$ For example, the students are explaining the robot's sudden stopping position (away from the mission table edges) as the reason is related to the approximate sensor measurements.

b. (For interfacing with sensors this level was merged with applying).

5. Evaluating the students demonstrate the evaluating level if they are:

a. (For input-output this level was merged with analyzing).

b. (Interfacing with sensors) criticizing, explaining and modifying the algorithm used for interfacing with sensors according to the robot's test results. For example, if the students used PID controller technique, they modify the algorithm to improve the robot's movements.

6. Creating the students demonstrate the creating level if they are:

a. (Input-output) coming up with a new, alternative or unexpected solution, or devising a new strategy for using the input-output concept.

b. (Interfacing with sensors) coming up with a new, alternative or unexpected algorithm.

\section{Data Analysis}

The students of each of the eight groups worked as a team on the activities for the FLL competition. Some students worked more on the scientific project part, but during the observations, the interviews and the competition day group interview, students used the plural pronoun 'we' (rather than 'I'), thus expressing the group's involvement and mutual responsibility. Therefore, we take the interviewed students as representative of the group as a whole, and not just to assess the learning of individual students.

The analysis of the data from the school year 2012-2013 focused on the observations of the students during the activities, and on the interviews of 15 students after the activities, while the analysis for year 2013-2014 focused on the group interviews during the competition day, except for Group 7, whose data was collected during the year and focused on the observations and the interviews of two students. The students who were interviewed by the researcher are referred to by $\mathrm{S}$ associated with a number as presented in Table 1 and Table 2 in section 3.1 above.

The research data collected were analyzed quantitatively and qualitatively. The quantitative analysis was relevant only to the investigation of students' attitudes and will be reported separately. The qualitative analysis examined the transcriptions of the observations and interviews that were videotaped. The transcriptions were analyzed according to the BT, as operationalized above. The analysis of the students' verbalization during the observations and their interaction with the representational models were inspired by Chi's (1997) verbal analysis for quantifying qualitative data.

\footnotetext{
${ }^{6}$ For this concept, the definition refers to the merged analyzing / evaluating level.
} 
The qualitative analysis regarding the CS discipline was performed as follows:

1. Segmenting each group's data according to the activity: the beginning, the middle and the end of the year (the competition).

2. Presenting the segments in tables; the rows of each table demonstrated a specific concept accompanied with detailed information and explanation.

3. An analysis for all the groups was conducted according to the segments presented in step (1) and further analyzed according to the concepts.

4. Another analysis was carried out for each of the concepts related to all groups.

5. The findings were summarized. The learning level of each group for each concept was presented in a table.

To ensure validity of the qualitative analysis, the researcher was not involved in the teaching and learning process, but only in preparing the research instruments and performing the data analysis. Triangulation among instruments was used to ensure the accuracy of the results. In addition, an independent analysis of the results was performed by a colleague to ensure theoretical validity. The few disagreements that occurred were negotiated until a consensus was reached.

\section{Findings}

This section presents the findings of learning CS during the preparation for the FLL local competitions. For each concept, the findings are summarized in a table for each group and then explained according to the BT. For groups that were investigated in both 2012-2013 and 2013-2014, there are two rows for the group in the table, one (white) for the first year and one (gray) for the second year. The results regarding learning are depicted by an arrow that starts at the initial BT level and ends at the BT level the students achieved at the end of the activities. The results of all groups in year 2013-2014 refer to the final period of the robotics activities (the competition day), except for Group 7 where the results refer to the whole period from the beginning of the activities until the competition day in 2013-2014.

\subsection{Input-Output}

\subsubsection{Summary of the Learning Levels that Were Achieved}

Table 3 summarizes the results of the input-output concepts.

Regarding the groups who had participated in the robotics activities for the first time in year 2012-2013, three out of the six groups (Group 5, Group 6, and Group 8 ) demonstrated learning at the analyzing / evaluating level of the BT. The groups started the activities at the remembering level. Three groups (Group 1, Group 2 and Group 7) started at the remembering level and at the end demonstrated a learning level of no more than the understanding / applying. The same results were demonstrated for the two groups (Group 3 and Group 4) who had previous experience in the robotics activities. 
Table 3

Results for the computer science concepts - input-output

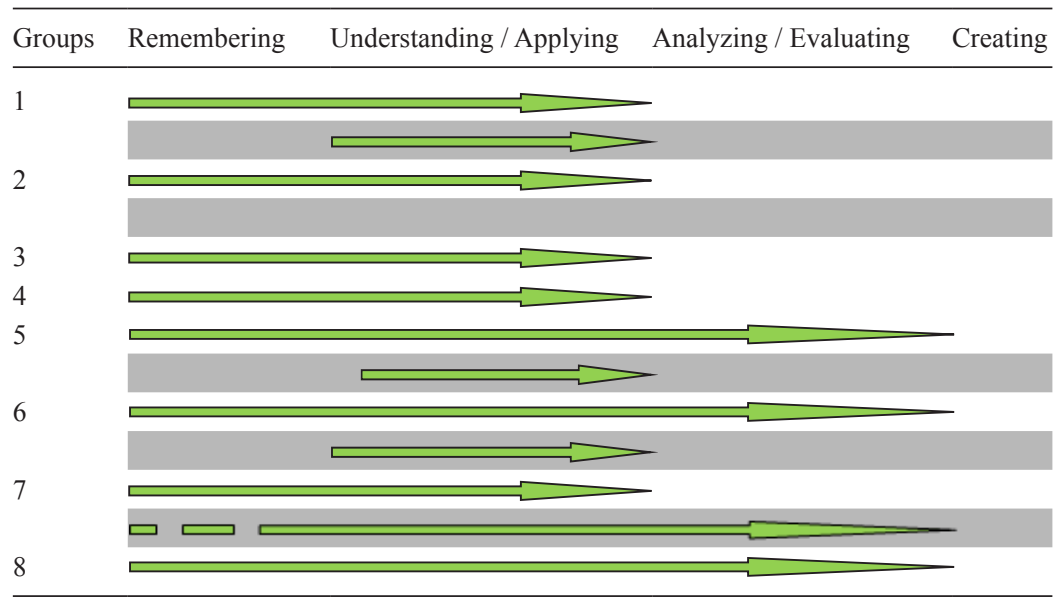

In year 2013-2014, one group (Group 7) demonstrated learning at the analyzing / evaluating level, and three groups (Group 1, Group 5 and Group 6) demonstrated learning at the understanding / applying level, while the data that was collected for Group 2 were not sufficient to demonstrate the learning level for this concept. The groups' starting level could not be determined because the data were gathered only during the group interview on the competition day. The results showed that for the year 2013-2014 Group 5 and Group 6 demonstrated a lower level of what they demonstrated the year before.

The data of Group 7 were collected throughout the school year and showed that the new students demonstrated the remembering level at the beginning of the activities (presented in the table above as dashed arrows) and joined the understanding / applying level with the experienced students when they participated in the school robotics class. Later in the activities, all students demonstrated the analyzing / evaluating level.

\subsubsection{Examples for the Learning Levels and Expanded Observations}

The following points were observed and can be illuminate and broaden these results:

- Limited learning: All the groups / students memorized the connection between the input-output devices with the NXT controller as they had been told, such as assigning the port ' $A$ ' always for the motor that is responsible for moving the manipulators. For example, the student S2 of Group 1 named the ports during the interview:

S1: [writing on one side of the NXT (see Fig. 1)] 'A' [port] is for the [motor connected to the] robot handle [a manipulator, a $\mathrm{LEGO}^{\circledR}$ construction for dragging and lifting] always. And ' $\mathrm{C}$ ' [port] is for the left wheel and ' $\mathrm{B}$ ' for the right one [wheel]. Here is the USB for the computer. Now here [writing on the other side of the NXT] we have ' 1 ', '2', ' 3 ', and ' 4 '. 


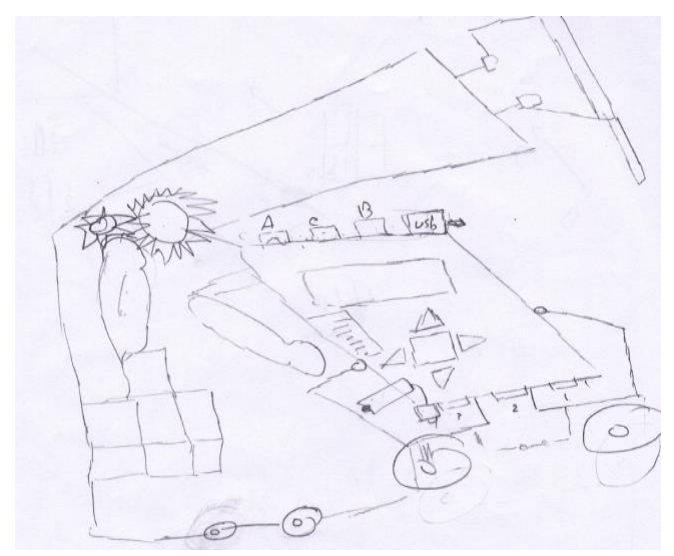

Fig. 1. Students' drawing of their robot.

When the students were asked if it is necessary to use that order, S12 of Group 3 responded during the interview:

S12: Well, 'B' and 'C' [ports] ... we can switch them, but 'A' [port], it has to be for [connected with] the handle [manipulator].

Students invariably used the same three outputs in this order. They memorized the location of input ports and the output port, but they did not know the difference since they only followed what they had been told.

- The difference between input and output: The location of the input ports on the NXT controller is on the side opposite of the location of the output ports. All students realized the locations and their connected devices, but treated them as all input or output. For example, Student S2 of Group 1 described the connections during the interview:

S2: The NXT is the brain of the robot. I mean without it the robot would not move. When we connected and downloaded [the program] from the computer to the NXT, the robot moved ... of course, by using the wires that are connected to the motors. The motors caused the handle [manipulator] and the wheels to operate. Here are the outputs ' $A$ ', 'B', and ' $C$ ' ... ' 1 ', '2', '3', and ' 4 ', each of these are outputs for the sensors [use].

$\mathrm{S} 2$ realized the places and the connections of the ports with the NXT controller, described the download of the program that caused the manipulators to operate by the motors, and mentioned that the wires connect the sensors, motors and the USB with the NXT controller. However, she referred to them as output, then and during the interview:

S2: No, these are inputs [thinking] these are inputs [pointing to the ' 1 ', '2', '3' and '4'], all of them. [Explaining by showing confidence] these four 
[pointing to ' 1 ', ' 2 ', ' 3 ' and ' 4 '] are inputs for the sensors, and these [pointing to the 'A', 'B' and ' $\mathrm{C}$ '] are inputs for the motors' movements. ... Actually in the NXT there are not only 7 outputs, we have 8 outputs. The 8 th is the speaker .... No ... these are outputs not inputs ... ah ... yes outputs ... the speaker is ... it gives sound. For example, when the robot reaches the destination, it gave a sound of 'Good bye' ... the sound is an output.

Some of the students, similar to S2, were confused when they were asked to explain the difference between input and output. Eventually, after reflection, S2 was able to understand the distinction between inputs and outputs, when she recalled the knowledge concerning the speaker as an output component and applied it to another situation (the sensors and motors). These students demonstrated the understanding / applying level but not higher.

- Developing a non-viable mental model: A few students confused downloading a program into NXT controller with inputting sensor's data. Although they knew that speakers are an output, they found this inconsistent with the mental model that the insertion of all wires is input. For example, Student S3 of Group 1 said during the interview:

S3: One output for the USB. The USB is an input ... we write a program and input it [download] from the computer to the NXT. The outputs are the sensors ... the same as the motors. Outputs are from the motors to the NXT. The input, which is the only USB, which we used to download the program ... these [pointing to the ports] are the input, from the motor to the NXT.

S3 referred to the connection of the USB as input and showed using their hands the downloading the program from the computer to the NXT. Student S1 mistakenly thought that the activity of connecting wires to the ports means input and that there is no difference between input and output:

S1: I know there are inputs and outputs but I do not know what the difference is or where are they. According to what I know we connect the wires, these [the components that are connected by the wires with the NXT] are inputs. ... Both [input and output] have the same meaning.

The mental model they created when they inserted the wires to the NXT caused them to call it input. S1 did not specify what are the inputs or the outputs but realized where each should be connected with the NXT controller.

- Explaining the input-output devices' functionality but not the concepts: Some students realized the functionality of the input-output devices. For example, Student S12 of Group 3 during the interview said:

S12: The motors need different programming orders than the sensors. The sensors sense something [surroundings], I mean if the robot needs to do a mission, the robot will do it even if the place is different. And if something got different [in the environment] the sensor reflection rate would change. It 
is like a local plan, we do not know the values before the sensor operates ... we have wires, these wires transfer the data by electronic charges, and the motor which is a device that transfers these data or order to movement.

S12 explained how the sensors read the surroundings and accordingly the robot moves or operates. S12 described how the data transferred and caused the robot to move. However, when S12 was asked about the concepts' terms:

S12: I heard that the inputs are the programs that we download from the computer to the NXT controller. While that outputs are the missions that the robot accomplish, or may be the orders that we download from the NXT to the computer.

S12 thought that the process of downloading from and to the computer represent the terms input and output. She did not connect what she just explained about the sensors and the motors with the concept's terms. Therefore, S12 and other students reacting similarly demonstrated the understanding / applying level.

- Implementing and explaining the data flow: After connecting the motors to the NXT, the students were asked to explain the data flow from the sensors through the NXT and then to the motors. Most of the students exemplified the data flow by talking about the medicine mission. For example, Student S5 of Group 5 exemplified during the interview:

S5: The robot gets the information from the sensor, analyzes it ... For example, [if the sensor reflects a color of] black or white, then the "reversed feeding" [as the student called it] which is when the program evaluates and orders the motor to move accordingly.

Some of the groups listed all the inputs and outputs peripherals in the robot, described the data flow from the input to generate output, applied the information about the concepts by using different sensors and controlling the robot's movements. They were able to differentiate between the concepts and relate the knowledge to the overall structure and behavior of the robot.

Moreover, the students were able to $u$ se the information about input and output for the purpose of moving from one programmed mission to another in a single touch sensor press, or using the NXT buttons (as if they were sensors) to select the specific program for each mission and thus gain more time for accomplishing the missions within the limited competition time. For example, Student S4 of Group 5 said during the interview:

S4: We used the buttons on the NXT as sensors; as it [the robot] waits until we press on one of the NXT button, then it will do the next mission [instead of clicking several buttons on the NXT fetching for the right program for a specific mission].

S4 explained, manipulated and evaluated the inputs and outputs to serve their needs. They expressed the manipulation to the overall structure either by using the 
NXT buttons or the touch sensor. S4 and other students reacting similarly demonstrated the analyzing / evaluating level, although it could also be considered to be creating because it was so unexpected.

- Connecting the information gained in a regular technology class with the robotics activities: Some of the students recalled their knowledge of the previous years' regular technology classes within the context of the robotics activities. For example, Student S10 of Group 7 said during the interview:

S10: I did not recognize the connection [of what she learned in the technology class and what she learned during the robotics activities] before [the interview]; this is awesome! ... Now I understood the concept [input-output] more [than her understanding from the technology class].

S10, during the interview, recalled that the concepts input-output were mentioned in her regular technology class last year and explained the relevant of these concepts to the activities. However, this was only during the interview, when she was asked if they learned the concept input-output before the activities.

\subsection{Interfacing with Sensors}

\subsubsection{Summary of the Learning Levels that Were Achieved}

The students needed to program the sensors for two missions: 1) using a color sensor to detect the green medicine; and 2) using a light or color sensor to enable the robot follow the black or colored line on the competition table. Table 4 summarizes the results regarding the concept of interfacing with the sensors.

Regarding the groups who had participated in the robotics activities for the first time in year 2012-2013, one group (Group 5) out of the six groups, demonstrated learning at

Table 4

Results for the computer science concepts - interfacing with sensors

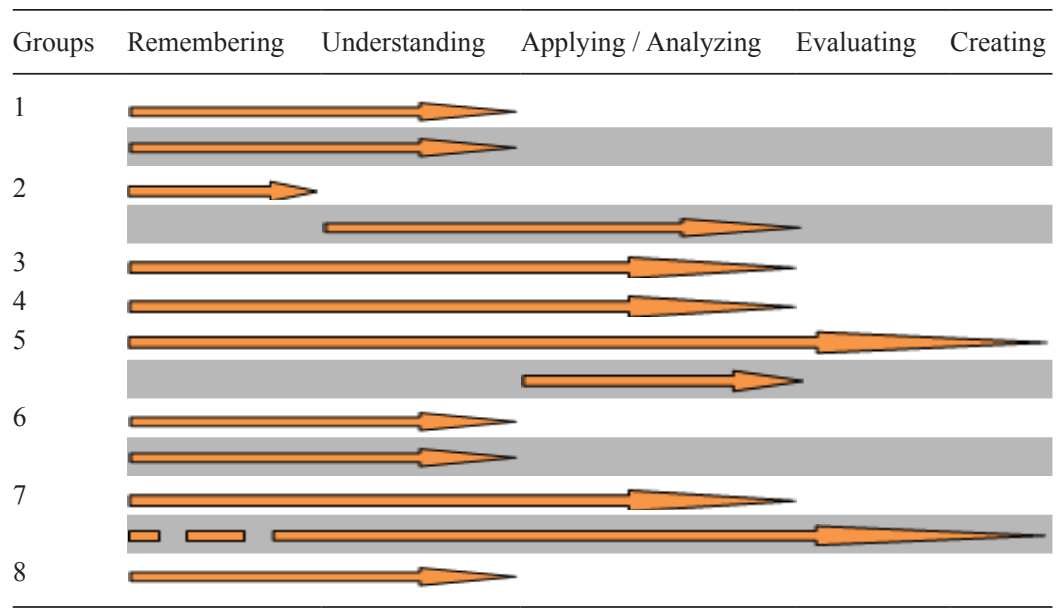


the evaluating level of the BT, and one (Group 7) demonstrated learning at the applying / analyzing. Both groups started the activities at the remembering level.

Three groups (Group 1, Group 6 and Group 8) demonstrated learning at the understanding level. The groups started the activities at the remembering level. Only one group (Group 2) demonstrated no more than the remembering level. As for the two groups (Group 3 and Group 4) who had previous experience in the robotics activities, they started learning at the remembering level and achieved learning at the applying / analyzing level.

In year 2013-2014, one group (Group 7) out of five demonstrated the level following the one they demonstrated the year before. They started at the applying / analyzing and achieved learning at the evaluating level. Two groups (Group 2 and Group 5) demonstrated learning at the applying / analyzing level. The students of Group 2 started at the understanding, which was the level following the one they had demonstrated the year before, while Group 5 demonstrated a level less than the one they had demonstrated the year before. Two groups (Group 1 and Group 6) demonstrated no more than understanding. These two groups' starting level was not clear because the data were gathered only during the group interview on the competition day.

The data of Group 7 were collected throughout the school year and showed that the new students demonstrated the remembering level at the beginning of the activities (presented in the table above as dashed arrows) and joined the applying / analyzing level with the experienced students when they participated in the school robotics class. Later in the activities, all students demonstrated the evaluating level.

\subsubsection{Examples for the Learning Levels and Expanded Observations}

The following points were observed and can be illuminate and broaden these results:

- Limited learning: All students followed the instructions presented in the LEGO ${ }^{\circledR}$ kit booklet to connect the light sensor. They recognized that the sensor block in the NXT software is used for the programming to interface with the sensors. They named the different kinds of sensors and briefly listed the purpose of using each one. For example, Student S15 of Group 8 listed the available sensors during the interview:

S15: The light sensor and color sensor for detecting the colors, the Gyro sensor, for detecting and measuring the angles, and the ultrasonic to let the robot avoid hitting the wall [competition table edges]. At the end we decided not to use any of the sensors...

S15 listed the kinds of sensors and their uses but the students of Group 8, at the end of the activities, caused the robot to move according to the measurements instead of using any sensors. Therefore, the students of Group 8 and other students reacting similarly demonstrated the remembering level.

- Implementing using sensors for specific reason: Most of the students described the overall process of the sensors' functionality. For example, Student S12 of Group 3 used the touch sensor for the purpose of moving after getting hit into the competition table edges. she said: 
S12: We used the touch sensor to avoid hitting [the robot] into the wall [competition table edges]. We used to have hard time when the robot hits into the wall and stop [not doing the next order]. The touch sensor made the robot stop and then move forward.

The robot switches to the next order / command (or in this case block) in the program when it finishes the current one. When the robot are forced to stop because of hitting an edge, it is actually operating to finish the order of moving until the time or distance assigned ended. The students of Group 3 used the touch sensor to cause the next command to operate and thus keep the robot moving. These students and other students reacting similarly demonstrated the applying / analyzing level.

- Using the dual- or multi-state technique / algorithm: One of the NXT blocks is a block for interfacing with sensors. By filling out the needed parameters, the sensor operates accordingly. For example, Student S3 of Group 1 explained the method used for interfacing with the color sensor:

S9: we programmed the robot so the sensor detects a color. The sensor's light turned on, and when it [the light attached with the color sensor] is on, the sensor detects the colors around it. There are colors that either reflect or absorb the light. The colors that reflect the light have rates of more than 50. While the colors that absorbs the light, usually have rates of less than 50. For example, we want the robot to move on [following] the black line [drawn on the competition table ground], the black color absorbs the light, so it is less than 50 . So when the sensor detects a color that has a rate of less than 50, we assign an order [command or added a block] to do some action such as stop, turn or move.

S3 explained the relevant knowledge of light reflection, described the method of reading the rate of reflection and manipulate accordingly. This method called dual-state method. Most of the groups' students referred to this method when describing the interface of sensors.

A few of the groups' students descried the multi-state method. For example, Student S6 of Group 6 mentioned during the interview:

S6: We determined the range of the colors; black, white, green and orange. Then we assigned the value in a loop. I remember using the switch [conditional statement block], if yes [the option within the range of a specific color], the robot should keep checking, otherwise stop ... and things like that [for the rest of the colors]. But we did not have time to do it; we left the medicine mission to the end.

S6 described the algorithm by using the visual blocks related to sensors for detecting several colors. S6 also interpreted the process related to the repetition and conditional statements. However, the students of Group 6 did not actually implement the program; instead, they decided to discard and skip the accomplishment 
of the medicine mission. Therefore, the students of Group 6 and the other students reacted similarly demonstrated the understanding level.

- Using the PID technique / algorithm and comparing the results: A PID controller modifies the output proportional (P) to the input value, its integral (I) and its derivative (D). This concept was mentioned by one of the mentors, but the students used only the simplest P (proportional) controller. The algorithm was used for the purpose of following the black line on the competition table ground. Student S4 explained the algorithm during the interview:

S4: First we dragged the light sensor [the software block] ... we had several laws that we wrote on a separate paper ... We started applying these laws one after another: First thing we subtracted the 'perfect point' -50, in order to cause the robot move on the edge that had $50 \%$ white and $50 \%$ black, then we looked at the 'proportional constant', which was the multiplication by 0.9 , because we did not want to cause the robot to move in a [noticeable] zigzag way. Then the program had to decide one of the two directions - subtract or add. ... [With an appropriate speed] ... we added the motor ' $\mathrm{B}$ ' [added a condition block and then a move block for ' $\mathrm{B}$ '] and on the other [side of the condition block] motor ' $\mathrm{C}$ ' [move block]. It depends on the robot's location; if it is on the right or the left side of the black line. All these are inside a big loop ... So the robot moved right, smoothly and straight.

In addition, Student S5 of the same group gave an example:

S5: If the sensor saw $60 \%$ [the reflection light rate] that means the robot was going to the white color a little, so we had an order to decrease that motor power and increase the other motor [each responsible for moving the front wheels], and the robot turned.

Both S4 and S5 of Group 5 described, exemplified, checked and critiqued the proportional method and modified the solution that caused the robot to move on the colored line with hardly any zigzag. Student S4 compared the experience of using sensors with the experience when the group started the activities without using any sensors. S4 reached to the conclusion that the group was wasting their time when they did not use any sensors. The Group 5 started the activities without using sensors, because they thought that using sensors might ruin the behavior of the robot, especially on the competition day that may have different environment (an issue mentioned by all groups). Subsequently, the students of Group 5 decided to use three sensors, which they programmed without assistance; they were highly motivated to extract information from sources such as online resources.

Although the students of Group 5 were confident of their work, the robot did not behave as expected on the competition day. Therefore, the students of Group 7, in year 2013-2014, realized the problem and developed an alternative plan. Student S16 explained the use of the gyro sensor during the interview: 
S16: I agree that the use of sensor was beneficial. But for the competition we were afraid of using sensors. We had two programs one interface with sensors and one without sensors. We used the one [program] without sensors.

The groups who used the sensors and explained the algorithms demonstrated the applying / analyzing, while the one who criticized the algorithms and tried to modify it to get better results demonstrated the evaluating level.

\subsection{Two Items in the Attitude Questionnaires that Dealt with CS}

Although the investigation of attitudes is beyond the scope of this paper, we bring two items of the questionnaires that are relevant to CS learning. (1) "I think computer science knowledge is necessary for robotics." (2) "My future career will not be in computer science." The results showed that around $85 \%$ of the students agreed on the importance of having computer science knowledge for the robotics activities. The percentage was high when they started the activities and slightly increased by the end. For the second item, most of the students responded 'not sure' in both the pre- and the post-questionnaires.

\section{Discussion}

\subsection{Meaningful Learning According to the Bloom Taxonomy}

Almost all the students demonstrated meaningful learning as a result of participation in the robotics competitions. Most of the groups demonstrated learning up to the level of understanding / applying, except for one group that demonstrated learning at the low level of remembering for the concept of interfacing with sensors. Some of the students reached higher levels of the BT like analyzing or evaluating. A closer examination of the findings yields the following results.

Most of the students achieved the level of understanding or applying for both concepts, that is, they connected the input-output devices with the NXT controller correctly and tried to interface with sensors, as required for completing one of the missions. However, the scope of their learning was narrow: they did not distinguish between inputs and outputs, and eventually decided to discard the missions that required the use of the sensors. Indeed, both concepts necessitate exploring and searching for information, in order to reach higher levels of learning.

Fewer students reached the level of analyzing or evaluating level. These students explained the concepts, differentiated between inputs and outputs, and used the relevant knowledge in modifying the structure or the algorithms. The common characteristics of these groups were the exploration of the resources and discovering new solutions, with or without help from the teacher or mentor. For example, Group 7 which reached the evaluating level for both concepts had a teacher who employed a guided discovery learning pedagogy, while there was limited involvement by the teacher in Group 5 which 
also reached the evaluating level for both concepts. This was compatible with Sullivan and Moriarty (2009); they examined the teacher's reflection on teaching and learning robotics through the discovery learning method, and found that the experience of finding information and solving unexpected problems was effective. We conclude that students and teachers need to be encouraged to work together in exploring and acquiring knowledge and in discovering new solutions.

Only one group (Group2) did not exceed the remembering level for the concept of interfacing with sensors. The students only listed the kinds of sensors available and their purposes. They could not describe their algorithm for interfacing with the light sensor even though it was part of the design. We believe that this poor performance was related to the teacher-centered instructional pedagogy that they experienced. The context - accomplishing the competition missions - certainly facilitates the use of these two CS concepts; however, the teacher's detailed instruction on how to use the sensors did not foster high levels of exploration. This is in contrast with the achievements of the other groups who reached higher levels of learning with teachers who were not using a fully teacher-centered pedagogy.

\subsection{Factors that Affect Learning in Robotics Competitions}

We found that certain factors characteristic of the robotics competitions seemed to play a role in determining the learning levels that the students achieved: (a) the competitive nature of the activities; (b) the teaching pedagogy; (c) the unstable nature of the design of the robots; (d) the curricular position of the activities.

The competitive nature of the activities. Two aspects of the competition influenced the students' learning: the mission requirements and the limited time available. The competition had a positive impact on students' learning, because they were challenged to solve problems in order to accomplish the missions. This is consistent with Melchior et al. (2005) who found that the FRC competition promoted a positive academic trajectory for its students. However, the competitive environment also had some negative impact. For example, some students did not attempt certain missions, because of the limited time they had thought that they would not be able to succeed in interfacing with the sensors. A few groups were able to manage their time and accomplish most of the missions-including the harder ones - so we cannot conclude that time limitations were the only negative factor for those students.

Teaching pedagogy. The results showed a high variability in the learning that the students achieved. As discussed above, discovery learning was explained variability between groups. Students experienced a teacher-centered pedagogy at the beginning of the activities, enabling to achieve the remembering level. Since most of the teachers had limited knowledge of robotics and the robotics competition, a shift to a learner-centered pedagogy occurred in most groups when the students and teachers realized that the shift was necessary in order to accomplish the missions. Both the students and the teachers (or in some cases the students alone) searched the available resources to construct more knowledge and to solve the unexpected problems. This supports the claim by Virnes, Su- 
tinen, and Kärnä-Lin (2008) that the advantage of robotics activities is that they offer opportunities for exploration due to the frequent occurrence of unexpected problems. This raises the possibility that teacher-centered pedagogy may not be effective in the context of robotics competitions.

The unstable nature of the design of the robot. Martin (2006) noted that the physical variability in real-world robots and the environment can help students deal with unexpected problems. Our findings showed that the teachers did not hide the fact that "robots do not drive straight" and pointed out that sensors are unreliable. Some students became discouraged and tried to eliminate sensors in their design, while other students took it as a challenge. Indeed, the solutions that the students presented as a challenge, did not work very well in the competition, but the students acknowledged the benefit of using sensors and felt proud of their accomplishments. This may have been due to the students' determination to succeed, which was observed during their design sessions and reported in the interviews.

The curricular position of the activities. Most of the students from Group 7 who had participated in 2012-2013 competition also participated in a robotics course that the school introduced the following year. The new students who joined the group demonstrated the remembering level at the beginning of the activities and were able to catch up with the students who had participated in the competition the previous year. All students eventually demonstrated learning up to the evaluating level, exploring information outside the scope of the available resources and producing impressive robot designs. This supports the findings of Melchior, et al. (2005) that the FRC helped participating schools in introducing robotics courses in fostering a positive school spirit. An alternative explanation might be that the new students were helped by their more experienced teammates, and they could have reached a similar level of learning if the activities had been extracurricular. However, the observations and interviews showed that the experienced teammates did not mentor the new students; furthermore, additional material was taught in class that had not been part of the competition. In other groups who participated for a second year in extra-curricular activities, we could not observe similar results. Although no direct help by the experienced students was observed, nevertheless, the new students seemed to learn faster in this context.

\section{Conclusions}

The research showed that robotics competitions are effective in achieving meaningful learning of computer science concepts. Most students reached the middle levels of the Bloom Taxonomy and some reached higher levels. The most successful learners were those who engaged in exploration of resources in order to learn new concepts and to solve problems they encountered.

The competitions had both positive and negative effects. On the positive side, many students displayed a determination to accomplish the missions that led to effective learning behaviors. On the negative side, learning opportunities were sometimes pushed aside 
in favor of constructing robots that tried to accomplish the missions. Further research is needed to determine the relative advantages and disadvantages of robotics competitions when compared with curricular robotics activities.

\section{References}

Anderson, L., Krathwohl, D., Airasian, P., Cruikshank, K., Mayer, R., Pintrich, P., Rath, J. and Wittrock, M. (eds.) (2001). A Taxonomy for Learning and Teaching and Assessing: A Revision of Bloom 's Taxonomy of Educational Objectives. Addison Wesley Longman.

Anderson, M., McKenzie, A., Wellman, B., Brown, M., Vrbsky, S. (2011). Affecting attitudes in first-year computer science using syntax-free robotics programming. ACM Inroads, 2(3), 51-57.

Ausubel, D. (1963). The Psychology of Meaningful Verbal Learning. New York, NY, Grune \& Stratton.

Ausubel, D. (2000). The Acquisition and Retention of Knowledge: A cognitive View. Dordrecht, the Netherlands, Kluwer Academic Publishers.

Bloom, B., Krathwohl, D. (1956). Taxonomy of Educational Objectives: The Classification of Educational Goals, by a Committee of College and University Examiners. Handbook 1: Cognitive Domain. New York, Longmans.

Botball website retrieved on April 2015 from http: / / www . botball . org

Chi, M., (1997). Quantifying qualitative analyses of verbal data: a practical guide. The Journal of the Learning Sciences, 6(3), 271-315.

Denning, P. (2010). The great principle of computing. The Scientific Research Society, 98, 369-372.

Denning, P., McGettrick, A. (2005). Recentering computer science. Communications of the ACM, 48(11), 15-19.

Denning, P., Comer, D., Gries, D., Mulder, M., Tucker, A., Turner, A., Young, P. (1989). Computing as a discipline. $A C M, 32(1), 9-23$.

Fagin, B., Merkle, L. (2003). Measuring the effectiveness of robots in teaching computer science. $A C M$ SIGCSE Bulletin, 35(1), 307-311.

FIRST Robotics Competition website retrieved on April 2015 from

http://www.usfirst.org/roboticsprograms/frc

FLL site Retrieved on April 2014 from http: / / firstlegoleague. org

Forehand, M. (2012). Bloom's Taxonomy, Georgia.

http://projects.coe.uga.edu/epltt/index.php?title=Bloom\%27s_Taxonomy

Howland, J.L., Jonassen, D., Marra, R.M. (2011). Meaningful Learning with Technology. (4 ${ }^{\text {th }}$ Ed.) Pearson Education, Inc.

Johnson, C., Fuller, U. (2006). Is bloom's taxonomy appropriate for computer science? In: Berglund, A. (Ed.). $6^{\text {th }}$ Baltic Sea Conference on Computing Education Research (Koli Calling 2006). Finland, Koli National Park, 115-118.

Kaloti-Hallak, F. (2014). The effect of Robotics Activities on Studetns' Learning and Attitudes. ICER'14.

Kumar, D. (2011). Learning computing with robots. Institute for Personal Robots in Education.

Lauwers, T., Nourbakhsh, I., Hamner, I. (2009). CSbots: design and deployment of a robot designed for the CS1 Classroom. ACM SIGCSE Bulletin, 41(1), 428-432.

Martin, F. (2001). Robotic Explorations: A hands-on Introduction to Engineering. Upper Saddle River, N.J.: Prentice Hall.

Martin, F. (2006). Real Robots Don't Drive Straight. American Association for Artificial Intelligence.

Mayer, R. (2002). Rote versus meaningful learning. Theory into Practice, 41(4), 226-232.

Melchior, A., Cohen, F., Cutter, T., Leavitt, T. (2005). More than Robots: An Evaluation of the FIRST Robotics Competition Participant and Institutional Impacts: Center for Youth and Communities, Brandeis University

Miller, D., Nourbakhsh, I., Siegwart, R. (2008). Robots for Education. Springer. 1283-1301.

Miller, D.P., Stein, C. (2000). "So that's what pi is for!" and other educational epiphanies from hands-on robotics. In: Druin, A., Hendler, J. Robots for Kids, Exploring New Technologies for Learning. Morgan Kaufmann Publishers, 219-244.

Riedo, F., Chevalier, M., Magnenat, S., Mondada, F. (2013). Thymio II, a robot that grows wiser with children. In: IEEE Workshop on Advanced Robotics and its Social Impacts (ARSO), 187-193. 
Robofest website retrieved on April 2015, from http://robofest. net

Sullivan, F. R. (2008). Robotics and science literacy: thinking skills, science process skills and systems understanding. The Journal of Research in Science Teaching, 45(3), 373-394.

Sullivan, F.R., Moriarty, M.A. (2009). Robotics and discovery learning: pedagogical beliefs, teacher practice, and technology integration. The Journal of Technology and Teacher Education, 17(1), 109-142.

Summet, J., Kumar, D., O’Hara, K., Walker, D., Ni, L., Blank, D., Balch, T. (2009). Personalizing CS1 with robots. ACM SIGCSE Bulletin, 41(1), 433-437.

TCFFHRC website retrieved on April 2015, from http://www. trincoll. edu/events/robot

Thompson, E., Luxton-Reilly, A., Whalley, J., Hu, M., Robbins, P. (2008). Bloom's taxonomy for CS assessment. Tenth Australian Computing Education Conference (ACE 2008) 79.

Trobaugh, J. (2010). Winning Design! LEGO Mindstorms NXT. Apress

Turkle, S., Papert, S. (1991). Epistemological pluralism. In: Harel, I., Papert, S. (Eds), Constructionism. Norwood, NJ, Ablex, 116-126.

Verner, I.M., Hershko, E. (2003). School graduation project in robot design: a case study of team learning experiences and outcomes. Journal of Teaching Education, 14(2). 40-55.

Virnes, M., Sutinen, E., Kärnä-Lin, E. (2008). How Children's Individual Needs Challenge the Design of Educational Robotics. Paper presented at the 7th international conference on Interaction design and children.

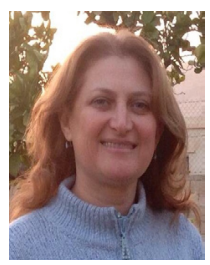

F. Kaloti-Hallak is a $\mathrm{PhD}$ student in the Department of Science Teaching of the Weizmann Institute of Science. She holds master degrees in Computer Information Systems from Eastern Michigan University in 2000 and Science Teaching from the Weizmann Institute of Science in 2011. Her research interests include middle-school computer science education and human-computer interaction. She has been a lecturer at the Department of Computer Science and Information Technology of Al-Quds University.

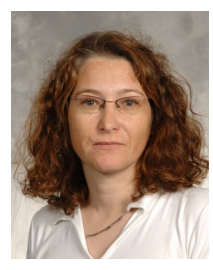

M. Armoni is a senior scientist at the Department of Science Teaching, Weizmann Institute of Science. She received her $\mathrm{PhD}$ from the School of Education in Tel-Aviv University, and her B.A. and M.Sc. in computer science from the Technion, Israel Institute of Technology. She has been engaged in computer science education for more than 20 years as a lecturer and a teacher, as a curricular developer, and as a researcher. She has co-authored several textbooks for high schools and for junior high schools. Her research interests are in the teaching and learning processes of computer science, specifically of various computer science fundamental ideas.

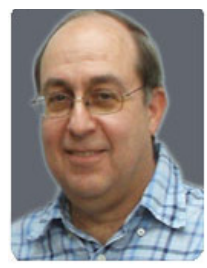

M. Ben-Ari is a professor in the Department of Science Teaching of the Weizmann Institute of Science. He holds a $\mathrm{PhD}$ degree in mathematics and computer science from the Tel Aviv University. He is the author of several textbooks on elementary computer science, mathematical logic and concurrent programming. In 2004, he received the ACM/SIGCSE Award for Outstanding Contributions to Computer Science Education, and in 2009 he was designated an ACM Distinguished Educator. 